\title{
Recent Development of Bifunctional Small Molecules to Study Metal-Amyloid- $\beta$ Species in Alzheimer's Disease
}

\author{
Joseph J. Braymer, ${ }^{1}$ Alaina S. DeToma, ${ }^{1}$ Jung-Suk Choi, ${ }^{2}$ Kristin S. Ko, ${ }^{1}$ and Mi Hee Lim ${ }^{1,2}$ \\ ${ }^{1}$ Department of Chemistry, University of Michigan, Ann Arbor, MI 48109-1055, USA \\ ${ }^{2}$ The Life Sciences Institute, University of Michigan, Ann Arbor, MI 48109-2216, USA
}

Correspondence should be addressed to Mi Hee Lim, mhlim@umich.edu

Received 18 September 2010; Accepted 25 October 2010

Academic Editor: Peter Faller

Copyright () 2011 Joseph J. Braymer et al. This is an open access article distributed under the Creative Commons Attribution License, which permits unrestricted use, distribution, and reproduction in any medium, provided the original work is properly cited.

\begin{abstract}
Alzheimer's disease $(\mathrm{AD})$ is a multifactorial neurodegenerative disease related to the deposition of aggregated amyloid- $\beta$ (A $\beta$ ) peptides in the brain. It has been proposed that metal ion dyshomeostasis and miscompartmentalization contribute to AD progression, especially as metal ions (e.g., $\mathrm{Cu}(\mathrm{II})$ and $\mathrm{Zn}(\mathrm{II})$ ) found in $\mathrm{A} \beta$ plaques of the diseased brain can bind to $\mathrm{A} \beta$ and be linked to aggregation and neurotoxicity. The role of metal ions in $\mathrm{AD}$ pathogenesis, however, is uncertain. To accelerate understanding in this area and contribute to therapeutic development, recent efforts to devise suitable chemical reagents that can target metal ions associated with $\mathrm{A} \beta$ have been made using rational structure-based design that combines two functions (metal chelation and $\mathrm{A} \beta$ interaction) in the same molecule. This paper presents bifunctional compounds developed by two different design strategies (linkage or incorporation) and discusses progress in their applications as chemical tools and/or potential therapeutics.
\end{abstract}

\section{Introduction}

Alzheimer's disease (AD) is a progressive neurodegenerative disorder that is a growing worldwide health concern among aging populations $[1,2]$. Attempts to unravel the underlying causes of $\mathrm{AD}$ have been made across a variety of disciplines, but despite the recognition of the physical and mental symptoms of the disease, little is understood about its etiology and pathological development [1-4]. It has been established, however, that accumulated amyloid- $\beta(\mathrm{A} \beta)$ plaques and neurofibrillary tangles are two of the defining pathological characteristics of AD [1-4].

One of the currently accepted hypotheses of $\mathrm{AD}$, the amyloid cascade hypothesis, states that $\mathrm{A} \beta$ and its aggregated forms may cause the neurodegeneration observed in diseased brains [1-7]. A $\beta$ is a peptide (38-43 amino acids in length) cleaved from the transmembrane amyloid precursor protein (APP) by $\beta$ - and $\gamma$-secretases [1,3-7]. Once generated, $\mathrm{A} \beta$ peptides can aggregate into oligomers, protofibrils, and fibrils that adopt the well-organized $\beta$-sheet structure [1, $3,4]$. To date, the aggregation pathways and neurotoxicity of $\mathrm{A} \beta$ have been extensively studied, but their involvement in the pathology of $\mathrm{AD}$ remains elusive $[1,3,4,7-12]$. Current evidence suggests that monomers and fibrils are relatively benign, while soluble oligomers, including dimers, are responsible for the neurotoxicity leading to dementia $[8,9]$. It also has been suggested that the formation of amyloid plaques may be an effect rather than a cause of $\mathrm{AD}$ development, and further insight into the biological role of $\mathrm{A} \beta$ may help elucidate this aspect [10-12]. Thus far, $\mathrm{A} \beta$ has been identified as a causative agent in $\mathrm{AD}$ and ongoing studies regarding the role of the $\mathrm{A} \beta$ peptide may contribute to the establishment of a fundamental understanding of $\mathrm{AD}$ neuropathogenesis.

Metal ion dyshomeostasis and miscompartmentalization also are thought to play a significant part in the progression of $\mathrm{AD}[1,3,4,13-23]$. The role of metal ions, including their effects on $\mathrm{A} \beta$ production/aggregation and neurotoxicity, is a relevant but contentious topic in the research field of $\mathrm{AD}$. Particularly, $\mathrm{Al}, \mathrm{Fe}, \mathrm{Cu}$, and $\mathrm{Zn}$ have been found to be associated with $\mathrm{A} \beta$ plaques in the brains of $\mathrm{AD}$ patients; however, like $\mathrm{A} \beta$, how these metals 
participate in AD pathogenesis is still unclear $[1,3,4,13-$ 25 ]. It has been suggested that $\mathrm{Al}$ (III) can cause a change in the $\mathrm{A} \beta$ conformation that stabilizes the oligomeric state and increases surface hydrophobicity, which may cause an increase in toxicity and membrane permeability $[16,19,26]$. The implication of $\mathrm{Al}(\mathrm{III})$ in $\mathrm{AD}$ has been debatable, as studies have been conducted using nonphysiological conditions [16].

Recent interest in this field has focused on the association of $\mathrm{Fe}(\mathrm{II} / \mathrm{III}), \mathrm{Cu}(\mathrm{I} / \mathrm{II})$, and $\mathrm{Zn}(\mathrm{II})$ with $\mathrm{AD}$ development $[1,3,4,13-25]$. Redox active $\mathrm{Fe}(\mathrm{II} / \mathrm{III})$ and $\mathrm{Cu}(\mathrm{I} / \mathrm{II})$ bound to $A \beta$ species can undergo Fenton chemistry leading to the generation of reactive oxygen species (ROS) such as hydrogen peroxide and hydroxyl radical. ROS can cause oxidative damage to biological molecules, which may trigger neurodegeneration. An additional effect of these ions, especially $\mathrm{Cu}(\mathrm{II})$ and $\mathrm{Zn}(\mathrm{II})$, in the $\mathrm{AD}$ brain is the facilitation of $\mathrm{A} \beta$ aggregation upon binding to the peptide. Elevated concentrations of $\mathrm{Cu}(\mathrm{II})$ and $\mathrm{Zn}$ (II) have been observed in senile plaques $[1,4,13-15,24,25]$; in particular, high concentrations of labile zinc are found in the regions of the brain most affected by $\mathrm{AD}$, the cortex and hippocampus $[4,13-17,19]$. Although these metal ions have been shown to be involved in $\mathrm{A} \beta$ aggregation events, their direct interactions with the peptide are not completely established. To understand metal coordination properties of $\mathrm{A} \beta$, structural investigations of metal-bound $\mathrm{A} \beta$ species have been performed employing a wide range of techniques such as nuclear magnetic resonance (NMR) spectroscopy, electron paramagnetic resonance (EPR) spectroscopy, circular dichroism (CD) spectroscopy, and mass spectrometry (MS) $[3,4,18,21,22]$. These studies have suggested that the coordination of $\mathrm{Cu}(\mathrm{II})$ and $\mathrm{Zn}$ (II) in $\mathrm{A} \beta$ species could occur via three histidine residues (H6, $\mathrm{H} 13$, and H14) and possibly another $\mathrm{N}$-terminal residue or the peptide backbone. Structural characterization of metal binding to $A \beta$ is of great interest and has been reviewed elsewhere $[4,18,21,22]$.

The involvement of metal ions in $\mathrm{AD}$ has been integrated into the established amyloid cascade hypothesis to form the "metal hypothesis of Alzheimer's disease," which states that the interactions between metal ions and $\mathrm{A} \beta$, as well as abnormal metal ion homeostasis, are connected with $\mathrm{AD}$ neuropathogenesis $[3,4,13-23]$. Based on this hypothesis, disruption of metal- $\mathrm{A} \beta$ interactions via metal chelation therapy has been proposed in order to reduce neurotoxicity of metal- $\mathrm{A} \beta$ species and restore metal ion homeostasis in the brain $[1,3,4,13,15-17,19,27-35]$. To date, several chelators such as EDTA $\left(N, N^{\prime}-1,2\right.$-ethanediylbis $[N$ (carboxymethyl)]glycine), clioquinol (CQ, 5-chloro-7-iodo8-hydroxyquinoline), and an 8-hydroxyquinoline derivative (PBT2) have been utilized as agents for metal ion chelation therapy in $\mathrm{AD}$ (Figure 1). Among these compounds, CQ and PBT2 improved cognition in phase II clinical trials [30-33]; however, long-term use of CQ is limited by a side effect, subacute myelo-optic neuropathy [36]. Overall, the studies using these and other traditional metal chelating agents have exhibited modulation of metal-induced $\mathrm{A} \beta$ events including aggregation and neurotoxicity in vitro and in vivo,<smiles>O=C(O)CN(CCN(CC(=O)O)CC(=O)O)CC(=O)O</smiles>



Clioquinol (CQ)

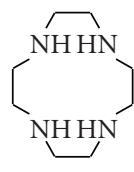

Cyclen
Figure 1: Chemical structures of EDTA ( $N, N^{\prime}$-1,2-ethaned- iylbis $[N$-(carboxymethyl) $]$ glycine), clioquinol (CQ, 5-chloro-7-iodo8 -hydroxyquinoline), and cyclen (cyc, 1,4,7,10-tetraazacyclododecane).

which suggests that the continued development of metal ion chelation therapy is a valuable pursuit for AD.

To obtain a greater understanding of the role of metal ions associated with $\mathrm{A} \beta$ and fashion potential therapeutic agents for $\mathrm{AD}$, improvement upon the metal ion chelation therapy approach would be desirable. Current efforts have been to apply rational structure-based design toward construction of small molecules that are capable of synergistically recognizing both metal ions and $\mathrm{A} \beta[4$, 37-42]. This approach could improve the limitations of the traditional metal chelating compounds (e.g., nonspecific metal chelation and low blood-brain barrier (BBB) permeability). The reported small molecules that have bifunctionality (metal chelation and $\mathrm{A} \beta$ interaction) are hybrids of a metal chelation moiety like EDTA, CQ, or cyclen (cyc, 1,4,7,10-tetraazacyclododecane) (Figure 1) and a known $\mathrm{A} \beta$ interaction scaffold, including ThT, the KLVFF peptide, curcumin, IMPY, and $p$-I-stilbene (ThT $=$ thioflavin $-\mathrm{T}, 2-[4-($ dimethylamino $)$ phenyl $]-3,6$-dimethylbenzothiazolium; curcumin $=(1 E, 6 E)-1,7$-bis $(4$-hydroxy3-methoxyphenyl)-1,6-heptadiene-3,5-dione; IMPY = 4-(7iodoimidazo[1,2-a]pyridin-2-yl)- $N, N$-dimethylaniline; $p$-Istilbene $=N, N$-dimethyl-4-[(1E)-2-(4-iodophenyl)ethenyl]benzenamine) (Figure 2) [4, 37-42]. Bifunctional small molecules targeted to metal ions surrounded by $\mathrm{A} \beta$ species have been developed following two different design principles (Figure 3, Approach I: linkage of metal chelation and $A \beta$ interaction structural components; Approach II: incorporation of a metal-binding site into an $A \beta$ interacting framework). The capability of these bifunctional compounds to regulate metal- $\mathrm{A} \beta$-involved events such as aggregation and neurotoxicity in vitro and in vivo is promising for further applications. The progress to date in the design and utilization of these compounds is discussed herein.

\section{Approach I: Linked Compounds}

The "linked" compounds are those in which a structural moiety for metal binding is connected to an $\mathrm{A} \beta$ interacting 
<smiles>Cc1ccc2c(c1)sc(-c1ccc(N(C)C)cc1)[n+]2C</smiles>

(ThT)

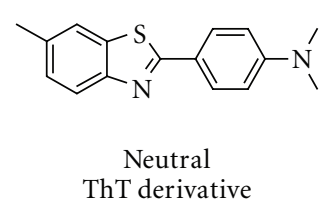

ThT derivative<smiles>CNc1ccc(-c2nc3ccc(O)cc3s2)cc1</smiles>

Pittsburgh Compound B<smiles>CC(C)C[C@H](NC(=O)C(N)CC=N)C(=O)NC(C(=O)N[C@@H](Cc1ccccc1)C(=O)NC(Cc1ccccc1)C(=O)O)C(C)C</smiles>

KLVFF

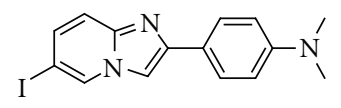

IMPY<smiles>COc1cc(/C=C/C(=O)CC(=O)/C=C/c2ccc(O)c(OC)c2)ccc1O</smiles>

Curcumin

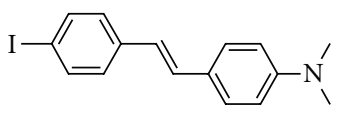

p-I-stilbene

Figure 2: Chemical structures of ThT (thioflavin-T), a neutral ThT derivative, Pittsburgh Compound B, the KLVFF peptide, curcumin, IMPY, and $p$-I-stilbene (ThT $=2$-[4-(dimethylamino)phenyl $]-3,6$-dimethylbenzothiazolium; neutral ThT derivative $=2$ (4-(dimethylamino)phenyl)-6-methylbenzothiazole; Pittsburgh Compound B = 2-[4-(methyl- ${ }^{11} \mathrm{C}$-amino)phenyl]-6-benzothiazolol; curcumin $=((1 E, 6 E)$-1,7-bis(4-hydroxy-3-methoxyphenyl)-1,6-heptadiene-3,5-dione; IMPY = 4-(7-iodoimidazo[1,2-a]pyridin-2-yl)- $N, N$ dimethylaniline; $p$-I-stilbene $=N, N$-dimethyl-4-[(1E)-2-(4-iodophenyl)ethenyl]benzenamine).

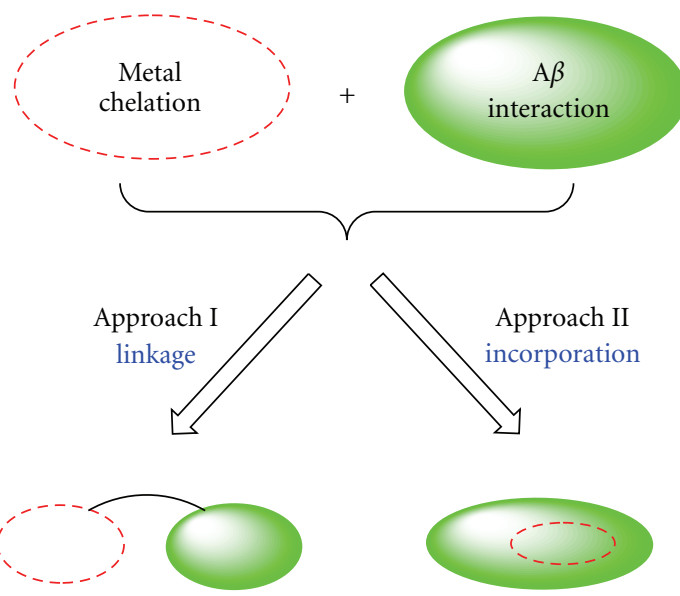

FIGURE 3: Overview of the two rational structure-based design strategies currently used to develop small molecules having bifunctionality (metal chelation and $\mathrm{A} \beta$ interaction). The first approach is based on the connection of metal chelation and $A \beta$ recognition structural moieties (Approach I: linkage). The second approach is direct incorporation of a metal chelation site into an $\mathrm{A} \beta$ interacting framework (Approach II: incorporation).

molecule (Approach I, Figure 3). The linked bifunctional molecules XH1 (N,N-bis[2-[[2-[[4-(2-benzothiazolyl) phenyl amino]-2-oxoethyl] (carboxymethyl)amino] ethyl]glycine), cyc-KLVFF, and cyc-Curcumin are discussed in this paper (Figure 4) [4, 37-40].

2.1. XH1. One of the small molecules most frequently used to understand $\mathrm{A} \beta$ aggregation pathways is ThT (Figure 2) [43-46]. Due to the ability of ThT to selectively bind to aggregated amyloid forms and thereby generate a fluorescence response, it can be employed to monitor the degree of $\mathrm{A} \beta$ aggregation. It has been proposed that ThT could be a useful framework to pursue in the development of $\mathrm{A} \beta$ imaging agents [47]. The application of ThT as a chemical probe in vivo, however, is limited by its positive charge, which impairs its ability to diffuse through the BBB [47-49]. Neutral ThT derivatives (Figure 2) prepared to alleviate this limitation of ThT exhibited more favorable properties, such as 600 -fold higher lipophilicity and greater binding affinity to $\mathrm{A} \beta$ [47]. These compounds also adhere to the restrictive terms of Lipinski's rules (low molecular weight (MW $\leq$ 450 ), relatively lipophilic ( $c \log P$, calculated logarithm of the octanol/water partition coefficient, $\leq 5)$, hydrogen-bond donor atoms (HBD $\leq 5)$, hydrogen-bond acceptor atoms $(\mathrm{HBA} \leq 10)$, and small polar surface area (PSA $\leq$ $\left.90 \AA^{2}\right)$ ), which, along with the calculated $\log B B$, can be used to predict $\mathrm{BBB}$ permeability $[48,49]$. The modifications of the neutral ThT derivatives have been conducted to devise applicable in vivo imaging agents. One of the most successful examples has been the preparation and utilization of a carbon-11-labeled compound, Pittsburgh Compound B (Figure 2), as an agent for positron emission tomography (PET) $[47,50,51]$. This compound has shown high affinity for $\mathrm{A} \beta$, specificity for staining plaques, and good brain entry and clearance. Overall, the ThT scaffold is an ideal candidate for chemical modification in order to produce new bifunctional molecules capable of targeting metal-A $\beta$ species (vide infra).

Dedeoglu et al. were the first to report a neutral ThTconjugated EDTA derivative, XH1 (Figure 4), for metalassociated $\mathrm{A} \beta$ species [39]. Computational ligand/receptor docking studies using XH1 indicated its specific interactions with $\mathrm{A} \beta_{1-40}$. XH1 was able to decrease $\mathrm{Zn}(\mathrm{II})$-induced 


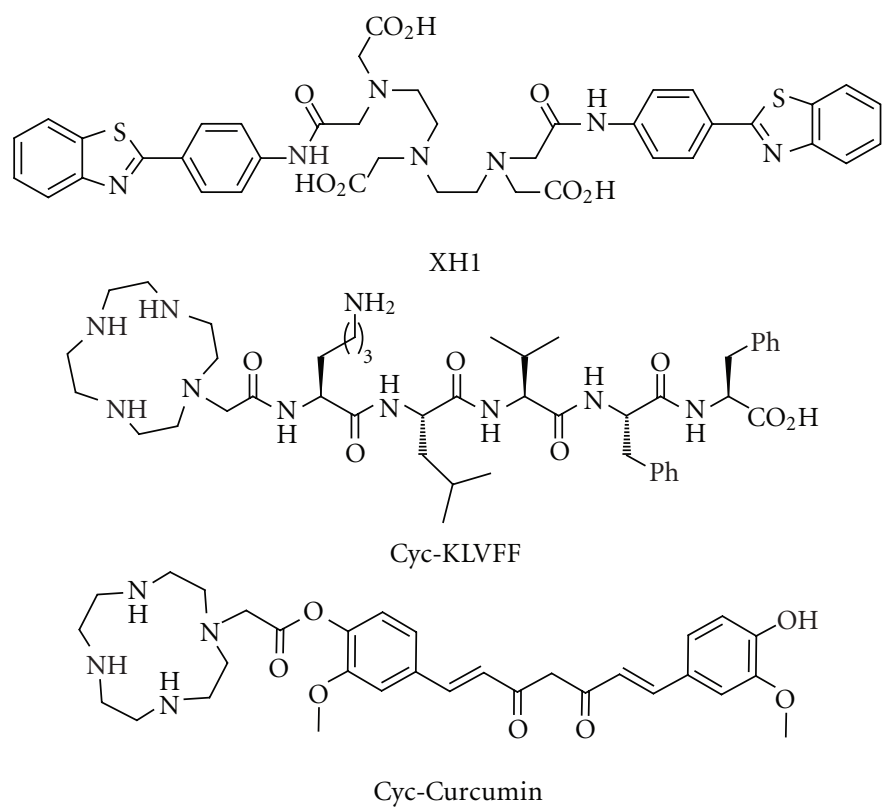

FIGURE 4: Chemical structures of small molecules XH1 (N,N-bis[2-[[2-[[4-(2-benzothiazolyl)phenyl]amino]-2-oxoethyl](carboxymethyl) amino] ethyl]glycine), cyc-KLVFF, and cyc-Curcumin that were designed by Approach I (Figure 3).

$\mathrm{A} \beta_{1-40}$ aggregation as well as APP expression in human $\mathrm{SH}-$ SY5Y neuroblastoma cells, indicating the possible modification of metal-A $\beta$ interactions by XH1. Given these positive results in vitro and no significant neurotoxicity at low micromolar concentrations in living cells, XH1 was tested further in the presenilin 1 (PS1)/APP transgenic mice model. While no behavior differences were observed in mice treated with XH1 for four weeks compared to those untreated, the deposition of $\mathrm{A} \beta$ plaques and the concentration of cortical $\mathrm{A} \beta$ were reduced in the treated mice. Therefore, these observations suggest that $\mathrm{XH} 1$ may be $\mathrm{BBB}$ permeable. Overall, the $\mathrm{A} \beta$ interaction and nontoxic nature of $\mathrm{XH} 1$ are a promising beginning for designing a new class of bifunctional small molecules.

2.2. Cyc-KLVFF. " $\beta$-sheet blockers" that interfere with amyloidogenesis by interacting with the portions of the peptide responsible for facilitating self-aggregation have been investigated [52-56]. The peptide sequence containing residues 16-20 (KLVFF) from the full-length peptide has been found to be the most effective at hindering $A \beta$ fibrillogenesis. A bifunctional small molecule, cyc-KLVFF (Figure 4), was fashioned by the coupling of the KLVFF peptide as the amyloid recognition moiety with the metal chelator cyclen (Figures 1 and 2) [40]. Cyclen is a macrocyclic metal chelator that can modulate $\mathrm{A} \beta$ aggregation and neurotoxicity in vitro and in cortical neuronal cells of C57BL6/J mice, and it has been shown that cyclen-Co(III) complexes have proteolytic activity $[57,58]$. Cyc-KLVFF (Figure 4 ) was effective toward reducing metal-triggered $\mathrm{A} \beta$ aggregation and neurotoxicity including $\mathrm{Cu}(\mathrm{II})$-induced $\mathrm{ROS}$ production in vitro and in neuronal cell culture [40]. Aggregated forms of the peptide also were cleaved upon incubation with cyc(Cu(II))-KLVFF complex. Apo-cyc-KLVFF was nontoxic in primary mouse $\mathrm{N} 2 \mathrm{a}$ neuroblastoma cells and could recover the toxicity of $\mathrm{A} \beta_{1-42}$ in cells pretreated with $\mathrm{Cu}(\mathrm{II})$. These results indicate the potential of apo-cyc-KLVFF to sequester $\mathrm{Cu}(\mathrm{II})$ from heterogeneous environments to protect against metal-A $\beta$ events. Cyc-KLVFF potentially is limited by nonspecific cleavage of other $\mathrm{Cu}$-containing proteins while $\mathrm{BBB}$ permeability may present an additional challenge due to the high MW of the compound [40, 48, 49]. Taken together, the design and studies of cyc-KLVFF suggest that the linkage of two structural frameworks for $\mathrm{A} \beta$ interaction and metal chelation (Approach I, Figure 3) could enhance reactivity toward metal-A $\beta$ species.

2.3. Cyc-Curcumin. Curcumin (Figure 2) has shown antiamyloidogenic, antioxidative, and anti-inflammatory properties [59-61]. The structure-activity relationships of $A \beta$ aggregation inhibitors based on curcumin have been studied, and three necessary structural features were identified: the presence of two terminal aromatic groups, the substitution of these aromatics, and the length and flexibility of the linker between the aromatic groups [62]. The reported properties of curcumin could afford a strong prototype recognition framework to incorporate into new bifunctional small molecules. Another bifunctional small molecule containing cyclen, cyc-Curcumin (Figure 4), was prepared to evaluate the ability of other recognition frameworks to function in this platform [40]. The corresponding metal complex, cyc $(\mathrm{Cu}(\mathrm{II}))$-Curcumin, presented $\mathrm{A} \beta$ aggregation inhibition and $\mathrm{A} \beta$ cleavage activity similar to $\mathrm{cyc}(\mathrm{Cu}(\mathrm{II}))$ KLVFF. The cyc $(\mathrm{Cu}(\mathrm{II}))$-Curcumin complex showed modest rescue of $\mathrm{A} \beta$-induced neurotoxicity. This compound demonstrates that linking a nonpeptide $\mathrm{A} \beta$ recognition/interaction 
molecule to a metal chelation framework may exert a similar effect on $\mathrm{A} \beta$ aggregation pathways, introducing another avenue to develop bifunctional compounds targeted to metal-A $\beta$ species following Approach I.

\section{Approach II: Incorporated Compounds}

The second class of bifunctional small compounds reviewed herein was designed based on direct incorporation of a metal-binding site into the structural framework of an $A \beta$ recognition/interaction molecule (Approach II, Figure 3). Utilizing Approach II, three categories of compounds have been reported: (a) the ThT-based molecules, HBX, HBT, BM, and their iodinated derivatives ( $\mathrm{HBX}=2$-(2-hydroxyphenyl) benzoxazole; HBT = 2-(2-hydroxyphenyl)benzothiazole; BM $=2$-(2-aminophenyl)benzimidazole $),(\mathrm{b})$ the IMPY derivative $(\mathbf{1})(\mathbf{1}=2$-[4-(dimethylamino) phenyl]imidazo[1,2-a] pyridine-8-ol), and (c) the stilbene derivative (2) $(2=$ $N^{1}, N^{1}{ }^{1}$-dimethyl- $N^{4}$-(pyridin-2-ylmethylene)benzene-1,4diamine) (Figure 5) [37, 38, 41, 42].

3.1. ThT Derivatives. The neutral ThT derivative (Figure 2) was used as a framework for designing bifunctional small molecules studied by Rodríguez-Rodríguez et al. [41]. By virtual screening of commercially available neutral ThT derivatives containing a bidentate metal chelation site, small molecules that could target metal ions surrounded by $\mathrm{A} \beta$ were identified. The criteria applied to select desired compounds required that their structures could be iodinated and satisfy the restrictive terms of Lipinski's rules, along with $\operatorname{logBB}[41,48,49]$. Their virtual screen identified 36 candidates, which were narrowed to three small molecules, HBX, HBT, and BM (Figure 5(a)). The iodinated versions of these three compounds, HBXI, HBTI, and BMI (Figure 5(a)), also were prepared and investigated due to their potential contribution to the development of new SPECT imaging agents $($ SPECT $=$ single photon emission computed tomography).

HBXI and HBTI were found to be primarily neutral at physiological $\mathrm{pH}$ (e.g., 7.4), which indicates potential $\mathrm{BBB}$ permeability in vivo while BMI existed in both the protonated and neutral forms at this $\mathrm{pH}$ [41]. The solution speciation studies regarding the binding affinities of $\mathrm{Cu}(\mathrm{II})$ and $\mathrm{Zn}(\mathrm{II})$ to these compounds suggest their capability to sequester metal ions associated with soluble forms of $\mathrm{A} \beta$. Inhibition of both $\mathrm{Cu}(\mathrm{II})$ - and $\mathrm{Zn}(\mathrm{II})$-induced $\mathrm{A} \beta$ aggregation was most significant for HBTI, while HBXI and $\mathrm{BMI}$ showed a similar effect only for $\mathrm{Cu}(\mathrm{II})$-triggered $\mathrm{A} \beta$ aggregation. Also, fluorescence measurements were conducted to assess the possible use of HBX, HBT, and their iodinated analogues as potential in vivo biomarkers for amyloid aggregates. Promisingly, HBX and HBT exhibited stronger fluorescence responses with mature amyloid fibrils than Pittsburgh Compound B, used in clinical trials. HBXI and HBTI demonstrate the potential for improving radioisotopic detection of $A \beta$ aggregates in the human brain [41]. Taken together, the studies using small, neutral ThT
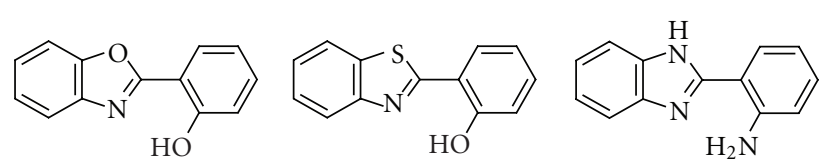

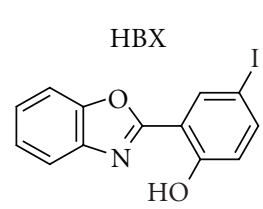

HBXI

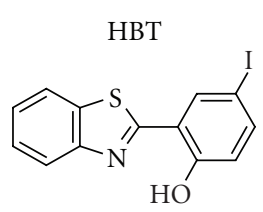

HBTI

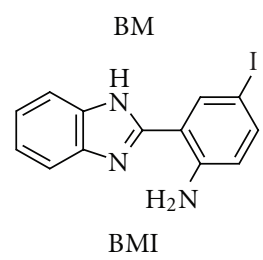

BMI (a) Neutral ThT drivatives.

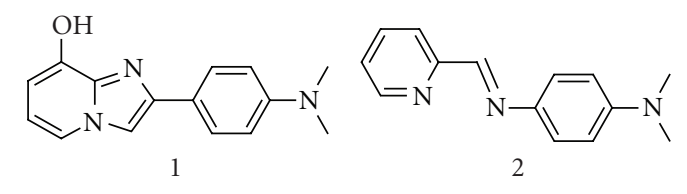

$\begin{array}{ll}\text { (b) IMPY derivative. } & \text { (c) Stilbene derivative. }\end{array}$

FIgURE 5: Chemical structures of small molecules (a) HBX/HBXI, HBT/HBTI, and BM/BMI, (b) 1 , and (c) 2 that were constructed employing Approach II (Figure 3) $(\mathrm{HBX}=2$-(2-hydroxyphenyl) benzoxazole; HBT $=2$-(2-hydroxyphenyl) benzothiazole; $\mathrm{BM}=$ 2-(2-aminophenyl)benzimidazole; 1 = 2-[4-(dimethylamino)phenyl]imidazo[1,2-a]pyridine-8-ol; $2=N^{1}, N^{1}$-dimethyl- $N^{4}$-(pyridin-2-ylmethylene)benzene-1,4-diamine).

derivatives suggest that bifunctional small molecules could have multiple applications in $\mathrm{AD}$ diagnosis and therapy.

3.2. IMPY Derivative. The need for in vivo $\mathrm{A} \beta$ plaque imaging molecules also has led to the development of a ThT analogue, IMPY (Figure 2) [63-68]. This radiolabeled iodinated ligand can be a useful SPECT reagent over some current PET probes for a number of reasons including practicality of administering the compound as well as cost and availability of SPECT equipment in clinical settings [64-66]. IMPY binds to $A \beta_{1-40}$ aggregates with nanomolar affinity and likely occupies a similar binding site as the thioflavin dyes due to its planarity and hydrophobicity. IMPY also has shown favorable pharmacokinetic properties in the Tg2576 and PS1/APP transgenic mouse models as well as safety in human patients [64-66]. The studies performed thus far illustrate the promise of radiolabeled IMPY as an in vivo SPECT imaging agent for potential diagnosis of $\mathrm{AD}$ in human patients.

The positive outcomes from studies with IMPY suggest that the modification of this framework to include a metal chelation site could be effective for developing bifunctional small molecules toward metal ions associated with $\mathrm{A} \beta$. One bifunctional IMPY derivative, $\mathbf{1}$, has been reported by Lim and coworkers (Figure 5(b)) [42]. An OH functionality was incorporated into the core framework of IMPY to generate a metal chelation site. Additionally, the structure fulfills the criteria of the restrictive terms of Lipinski's rules and the $\log \mathrm{BB}$ values, indicating that it may be drug-like and BBB permeable $[48,49]$. Along with metal-binding studies of $\mathbf{1}$ by UV-visible spectroscopy, two-dimensional (2D) 
${ }^{1} \mathrm{H}_{-}{ }^{15} \mathrm{~N}$ TROSY-HSQC NMR spectroscopy was employed in order to understand the interaction of 1 with $A \beta_{1-40}$ monomer $(\mathrm{TROSY}=$ transverse relaxation optimized spectroscopy; HSQC = heteronuclear single quantum correlation). Changes in the shifts of the NMR spectrum indicated that 1 interacts with $\mathrm{A} \beta$ residues including $\mathrm{E} 11$ and $\mathrm{H} 13$. Based on the close proximity of these residues to the metal chelation site (H6, H13, and H14) $[3,4,18,21,22], 1$ could possibly interact with metal ions in that portion of the peptide. This implies that $\mathbf{1}$ may have the potential to block $\mathrm{A} \beta$ fibrillogenesis from the monomeric state via disruption of metal-A $\beta$ interactions. Compared with the traditional metal chelators $\mathrm{CQ}$, phen (1,10-phenanthroline), and EDTA, 1 more effectively inhibited $\mathrm{Cu}(\mathrm{II})$-triggered $\mathrm{A} \beta$ aggregation and disassembled $\mathrm{Cu}(\mathrm{II})$-associated $\mathrm{A} \beta$ aggregates [42]. Furthermore, 1 was able to modulate ROS generated by $\mathrm{Cu}-\mathrm{A} \beta$ species. Although this compound showed cytotoxicity in human neuroblastoma cells at low micromolar concentrations, the favorable reactivity toward $\mathrm{Cu}(\mathrm{II})$-associated $\mathrm{A} \beta$ aggregation pathways warrants further chemical modifications of the IMPY scaffold for serving in future investigations.

3.3. Stilbene Derivative. Stilbene derivatives (Figure 2) have been widely devised and used as imaging agents for amyloid plaques [69-71]. Overall, stilbene derivatives are small, simple structures that could be labeled easily for in vivo imaging applications. While trans-stilbene has low affinity for $\mathrm{A} \beta$ aggregates, derivatives that contain electron-donating functionalities such as $p-\mathrm{N}\left(\mathrm{CH}_{3}\right)_{2}, p-\mathrm{OCH}_{3}$, or $p-\mathrm{OH}$ groups bind to $A \beta$ with higher affinity. These characteristics have made it an exemplar framework to modify for construction of bifunctional molecules. Thus, Hindo et al. have recently reported a stilbene derivative (2, Figure 5(c)) containing two $\mathrm{N}$ donor atoms as a bidentate metal chelation site [42]. Based on the restrictive terms of Lipinski's rules and the calculated $\log \mathrm{BB}$ value, 2 satisfies the requirements for potential $\mathrm{BBB}$ permeability $[48,49]$.

The stilbene derivative, 2 , presented encouraging reactivity toward metal-A $\beta$ species [42]. This molecule was shown to interact with $\mathrm{Cu}(\mathrm{II})$ studied by UV-visible spectroscopy and the interaction of the compound with $\mathrm{A} \beta_{1-40}$ monomer was investigated using $2 \mathrm{D}{ }^{1} \mathrm{H}_{-}{ }^{15} \mathrm{~N}$ TROSY-HSQC NMR spectroscopy. Similar to $\mathbf{1}$, upon addition of $\mathbf{2}$ to the peptide solution, the residues E11 and H13 were most significantly shifted, which suggests close contact of 2 with the metalbinding site in $\mathrm{A} \beta$. The bifunctional compound 2 not only controlled $\mathrm{Cu}(\mathrm{II})$-induced formation of $\mathrm{A} \beta$ aggregation but also disaggregated preformed $\mathrm{Cu}(\mathrm{II})$-treated $\mathrm{A} \beta$ aggregates. In addition, this compound attenuated ROS formation by $\mathrm{Cu}-\mathrm{A} \beta$ species, indicated no cytotoxicity up to high micromolar concentrations, and, more importantly, was capable of diminishing neurotoxicity of $\mathrm{Cu}-\mathrm{A} \beta$ species in human neuroblastoma cells. Though 2 has shown promising results thus far, the instability of this compound in aqueous media due to the susceptibility of the imine functionality to hydrolysis would hinder its in vivo applications. Therefore, structural modifications of 2 will lead to the next generation of biologically compatible small molecules as chemical tools and/or potential therapeutic agents for $\mathrm{AD}$ [72].

\section{Conclusion}

Metal ions associated with $A \beta$ have been suggested to be related to $\mathrm{AD}$ neuropathogenesis; however, the detailed mechanisms are not fully understood. To elucidate the role of metal ions surrounded by $A \beta$ and eventually to diagnose, treat, and prevent $\mathrm{AD}$, small molecules that have bifunctionality (metal chelation and $\mathrm{A} \beta$ interaction) have been designed as chemical tools and/or potential therapeutic agents based on the two rational structurebased design strategies. The first approach involves linking two structural components for metal chelation and $\mathrm{A} \beta$ interaction. According to this approach, XH1, cyc-KLVFF, and cyc-Curcumin were constructed by combining the $\mathrm{A} \beta$ recognition/interaction molecules (ThT, the KLVFF peptide, or curcumin) with metal chelation moieties (EDTA or cyclen). The second approach represents direct incorporation of $\mathrm{N}$ and/or $\mathrm{O}$ donor atoms for metal chelation into $\mathrm{A} \beta$ interacting frameworks (ThT, IMPY, or $p$-I-stilbene) producing $\mathrm{HBX} / \mathrm{HBXI}, \mathrm{HBT} / \mathrm{HBTI}, \mathrm{BM} / \mathrm{BMI}, \mathbf{1}$, and $\mathbf{2}$. The bifunctional compounds described in this paper have shown promising preliminary results toward metal-induced $\mathrm{A} \beta$ aggregation and neurotoxicity in vitro and/or in vivo; however, comprehensive in vivo studies of these molecules would be valuable. Common challenges of developing effective small molecules in biological systems (in particular, in the brain) include optimization of BBB permeability, stability, and toxicity in order to accomplish their future applications. Overall, the bifunctional small molecules discussed herein have laid a foundation for the emerging field of rational structure-based design of small molecules for targeting metal ions surrounded by $\mathrm{A} \beta$ species and regulating metal-involved $\mathrm{A} \beta$ events. Future endeavors in this area will provide inspiration for uncovering details of the roles of metal- $A \beta$ species in $\mathrm{AD}$ neuropathogenesis and may offer insight into the applicability to and understanding of other neurodegenerative diseases.

\section{Acknowledgments}

This work was supported by generous startup funding and a Rackham Faculty Grant from the Horace H. Rackham School of Graduate Studies from the University of Michigan, the Alzheimer's Art Quilt Initiative (AAQI), as well as the Alzheimer's Association (NIRG-10-172326) (to M. H. Lim). A. S. DeToma thanks the Graduate Assistance in Areas of National Need Fellowship from the University of Michigan. J.-S. Choi is grateful to the National Research Foundation of Korea funded by the Korean Government for a Postdoctoral Fellowship (NRF-2009-352-F00042). The authors thank Nichole Schmidt for helpful assistance. J. J. Braymer and A. S. DeToma contributed equally to this paper. 


\section{References}

[1] R. Jakob-Roetne and H. Jacobsen, "Alzheimer's disease: from pathology to therapeutic approaches," Angewandte Chemie International Edition, vol. 48, no. 17, pp. 3030-3059, 2009.

[2] M. Citron, "Alzheimer's disease: strategies for disease modification," Nature Reviews Drug Discovery, vol. 9, no. 5, pp. 387398,2010

[3] A. Rauk, "The chemistry of Alzheimer's disease," Chemical Society Reviews, vol. 38, no. 9, pp. 2698-2715, 2009.

[4] L. E. Scott and C. Orvig, "Medicinal inorganic chemistry approaches to passivation and removal of aberrant metal ions in disease," Chemical Reviews, vol. 109, no. 10, pp. 4885-4910, 2009.

[5] J. A. Hardy and G. A. Higgins, "Alzheimer's disease: the amyloid cascade hypothesis," Science, vol. 256, no. 5054, pp. 184-185, 1992.

[6] J. Hardy and D. J. Selkoe, "The amyloid hypothesis of Alzheimer's disease: progress and problems on the road to therapeutics," Science, vol. 297, no. 5580, pp. 353-356, 2002.

[7] G. Verdile, S. Fuller, C. S. Atwood, S. M. Laws, S. E. Gandy, and R. N. Martins, "The role of beta amyloid in Alzheimer's disease: still a cause of everything or the only one who got caught?" Pharmacological Research, vol. 50, no. 4, pp. 397-409, 2004.

[8] C. Haass and D. J. Selkoe, "Soluble protein oligomers in neurodegeneration: lessons from the Alzheimer's amyloid $\beta$ peptide," Nature Reviews Molecular Cell Biology, vol. 8, no. 2, pp. 101-112, 2007.

[9] G. M. Shankar, S. Li, T. H. Mehta et al., "Amyloid- $\beta$ protein dimers isolated directly from Alzheimer's brains impair synaptic plasticity and memory," Nature Medicine, vol. 14, no. 8, pp. 837-842, 2008.

[10] H.-G. Lee, G. Casadesus, X. Zhu, A. Takeda, G. Perry, and M. A. Smith, "Challenging the amyloid cascade hypothesis: senile plaques and amyloid- $\beta$ as protective adaptations to Alzheimer disease," Annals of the New York Academy of Sciences, vol. 1019, pp. 1-4, 2004.

[11] S. J. Soscia, J. E. Kirby, K. J. Washicosky et al., “The Alzheimer's disease-associated amyloid $\beta$-protein is an antimicrobial peptide," PLoS ONE, vol. 5, no. 3, article no. e9505, 2010.

[12] J. J. Palop and L. Mucke, "Amyloid- $\beta$-induced neuronal dysfunction in Alzheimer's disease: from synapses toward neural networks," Nature Neuroscience, vol. 13, no. 7, pp. 812$818,2010$.

[13] C. J. Maynard, A. I. Bush, C. L. Masters, R. Cappai, and Q.-X. Li, "Metals and amyloid- $\beta$ in Alzheimer's disease," International Journal of Experimental Pathology, vol. 86, no. 3, pp. 147-159, 2005.

[14] K. J. Barnham and A. I. Bush, "Metals in Alzheimer's and Parkinson's diseases," Current Opinion in Chemical Biology, vol. 12, no. 2, pp. 222-228, 2008.

[15] A. I. Bush and R. E. Tanzi, "Therapeutics for Alzheimer's disease based on the metal hypothesis," Neurotherapeutics, vol. 5, no. 3, pp. 421-432, 2008.

[16] J. A. Duce and A. I. Bush, "Biological metals and Alzheimer's disease: implications for therapeutics and diagnostics," Progress in Neurobiology, vol. 92, no. 1, pp. 1-18, 2010.

[17] F. Molina-Holgado, R. C. Hider, A. Gaeta, R. Williams, and P. Francis, "Metals ions and neurodegeneration," Biometals, vol. 20, no. 3-4, pp. 639-654, 2007.

[18] E. Gaggelli, H. Kozlowski, D. Valensin, and G. Valensin,
"Copper homeostasis and neurodegenerative disorders (Alzheimer's, prion, and Parkinson's diseases and amyotrophic lateral sclerosis)," Chemical Reviews, vol. 106, no. 6, pp. 19952044, 2006.

[19] P. Zatta, D. Drago, S. Bolognin, and S. L. Sensi, "Alzheimer's disease, metal ions and metal homeostatic therapy," Trends in Pharmacological Sciences, vol. 30, no. 7, pp. 346-355, 2009.

[20] X. Zhu, B. Su, X. Wang, M. A. Smith, and G. Perry, "Causes of oxidative stress in Alzheimer disease," Cellular and Molecular Life Sciences, vol. 64, no. 17, pp. 2202-2210, 2007.

[21] P. Faller, "Copper and zinc binding to amyloid- $\beta$ : coordination, dynamics, aggregation, reactivity and metal-ion transfer," ChemBioChem, vol. 10, no. 18, pp. 2837-2845, 2009.

[22] P. Faller and C. Hureau, "Bioinorganic chemistry of copper and zinc ions coordinated to amyloid- $\beta$ peptide," Dalton Transactions, no. 7, pp. 1080-1094, 2009.

[23] C. Hureau and P. Faller, "A $\beta$-mediated ROS production by $\mathrm{Cu}$ ions: structural insights, mechanisms and relevance to Alzheimer's disease," Biochimie, vol. 91, no. 10, pp. 1212-1217, 2009.

[24] M. A. Lovell, J. D. Robertson, W. J. Teesdale, J. L. Campbell, and W. R. Markesbery, "Copper, iron and zinc in Alzheimer's disease senile plaques," Journal of the Neurological Sciences, vol. 158, no. 1, pp. 47-52, 1998.

[25] L. M. Miller, Q. Wang, T. P. Telivala, R. J. Smith, A. Lanzirotti, and J. Miklossy, "Synchrotron-based infrared and $\mathrm{X}$-ray imaging shows focalized accumulation of $\mathrm{Cu}$ and $\mathrm{Zn}$ co-localized with $\beta$-amyloid deposits in Alzheimer's disease," Journal of Structural Biology, vol. 155, no. 1, pp. 30-37, 2006.

[26] F. Ricchelli, D. Drago, B. Filippi, G. Tognon, and P. Zatta, "Aluminum-triggered structural modifications and aggregation of $\beta$-amyloids," Cellular and Molecular Life Sciences, vol. 62, no. 15, pp. 1724-1733, 2005.

[27] M. P. Cuajungco, K. Y. Fagét, X. Huang, R. E. Tanzi, and A. I. Bush, "Metal chelation as a potential therapy for Alzheimer's disease," Annals of the New York Academy of Sciences, vol. 920, pp. 292-304, 2000.

[28] P. J. Crouch, A. R. White, and A. I. Bush, "The modulation of metal bio-availability as a therapeutic strategy for the treatment of Alzheimer's disease," The FEBS Journal, vol. 274, no. 15, pp. 3775-3783, 2007.

[29] S. Bolognin, D. Drago, L. Messori, and P. Zatta, "Chelation therapy for neurodegenerative diseases," Medicinal Research Reviews, vol. 29, no. 4, pp. 547-570, 2009.

[30] R. A. Cherny, C. S. Atwood, M. E. Xilinas et al., "Treatment with a copper-zinc chelator markedly and rapidly inhibits $\beta$-amyloid accumulation in Alzheimer's disease transgenic mice," Neuron, vol. 30, no. 3, pp. 665-676, 2001.

[31] C. W. Ritchie, A. I. Bush, A. Mackinnon et al., "Metal-protein attenuation with iodochlorhydroxyquin (clioquinol) targeting $\mathrm{A} \beta$ amyloid deposition and toxicity in Alzheimer disease: a pilot phase 2 clinical trial," Archives of Neurology, vol. 60, no. 12, pp. 1685-1691, 2003.

[32] P. A. Adlard, R. A. Cherny, D. I. Finkelstein et al., "Rapid restoration of cognition in Alzheimer's transgenic mice with 8-hydroxy quinoline analogs is associated with decreased interstitial A $\beta$," Neuron, vol. 59, no. 1, pp. 43-55, 2008.

[33] L. Lannfelt, K. Blennow, H. Zetterberg et al., "Safety, efficacy, and biomarker findings of PBT2 in targeting $\mathrm{A} \beta$ as a modifying therapy for Alzheimer's disease: a phase IIa, double-blind, randomised, placebo-controlled trial," The Lancet Neurology, vol. 7, no. 9, pp. 779-786, 2008.

[34] M. B. Cardelli, M. Russell, C. A. Bagne, and N. Pomara, "Chelation therapy. Unproved modality in the treatment of 
Alzheimer-type dementia," Journal of the American Geriatrics Society, vol. 33, no. 8, pp. 548-551, 1985.

[35] J.-Y. Lee, J. E. Friedman, I. Angel, A. Kozak, and J.-Y. Koh, “The lipophilic metal chelator DP-109 reduces amyloid pathology in brains of human $\beta$-amyloid precursor protein transgenic mice," Neurobiology of Aging, vol. 25, no. 10, pp. 1315-1321, 2004.

[36] J. L. Arbiser, S.-K. Kraeft, R. van Leeuwen et al., "Clioquinolzinc chelate: a candidate causative agent of subacute myelooptic neuropathy," Molecular Medicine, vol. 4, no. 10, pp. 665670, 1998

[37] C. Hureau, I. Sasaki, E. Gras, and P. Faller, "Two functions, one molecule: a metal-binding and a targeting moiety to combat Alzheimer's disease," ChemBioChem, vol. 11, no. 7, pp. 950953, 2010

[38] L. R. Perez and K. J. Franz, "Minding metals: tailoring multifunctional chelating agents for neurodegenerative disease," Dalton Transactions, vol. 39, no. 9, pp. 2177-2187, 2010.

[39] A. Dedeoglu, K. Cormier, S. Payton et al., "Preliminary studies of a novel bifunctional metal chelator targeting Alzheimer's amyloidogenesis," Experimental Gerontology, vol. 39, no. 1112, pp. 1641-1649, 2004.

[40] W.-h. Wu, P. Lei, Q. Liu et al., "Sequestration of copper from $\beta$-amyloid promotes selective lysis by cyclen-hybrid cleavage agents," Journal of Biological Chemistry, vol. 283, no. 46, pp. 31657-31664, 2008.

[41] C. Rodríguez-Rodríguez, N. Sánchez de Groot, A. Rimola et al., "Design, selection, and characterization of thioflavinbased intercalation compounds with metal chelating properties for application in Alzheimer's disease," Journal of the American Chemical Society, vol. 131, no. 4, pp. 1436-1451, 2009.

[42] S. S. Hindo, A. M. Mancino, J. J. Braymer et al., "Small molecule modulators of copper-induced A $\beta$ aggregation," Journal of the American Chemical Society, vol. 131, no. 46, pp. 16663-16665, 2009.

[43] P. S. Vassar and C. F. A. Culling, "Fluorescent stains, with special reference to amyloid and connective tissues," Archives of Pathology, vol. 68, no. 5, pp. 487-498, 1959.

[44] H. LeVine III, "Thioflavine $\mathrm{T}$ interaction with synthetic Alzheimer's disease $\beta$-amyloid peptides: detection of amyloid aggregation in solution," Protein Science, vol. 2, no. 3, pp. 404410, 1993.

[45] R. Leuma Yona, S. Mazères, P. Faller, and E. Gras, “Thioflavin derivatives as markers for amyloid- $\beta$ fibrils: insights into structural features important for high-affinity binding," ChemMedChem, vol. 3, no. 1, pp. 63-66, 2008.

[46] C. Rodríguez-Rodríguez, A. Rimola, L. Rodríguez-Santiago et al., "Crystal structure of thioflavin-T and its binding to amyloid fibrils: insights at the molecular level," Chemical Communications, vol. 46, no. 7, pp. 1156-1158, 2010.

[47] W. E. Klunk, Y. Wang, G.-f. Huang, M. L. Debnath, D. P. Holt, and C. A. Mathis, "Uncharged thioflavin-T derivatives bind to amyloid-beta protein with high affinity and readily enter the brain," Life Sciences, vol. 69, no. 13, pp. 1471-1484, 2001.

[48] C. A. Lipinski, F. Lombardo, B. W. Dominy, and P. J. Feeney, "Experimental and computational approaches to estimate solubility and permeability in drug discovery and development settings," Advanced Drug Delivery Reviews, vol. 46, no. 1-3, pp. 3-26, 2001.

[49] D. E. Clark and S. D. Pickett, "Computational methods for the prediction of 'drug-likeness'”, Drug Discovery Today, vol. 5, no. 2, pp. 49-58, 2000.

[50] W. E. Klunk, H. Engler, A. Nordberg et al., "Imaging brain amyloid in Alzheimer's disease with Pittsburgh compound-B," Annals of Neurology, vol. 55, no. 3, pp. 306-319, 2004.

[51] D. A. Wolk and W. E. Klunk, "Update on amyloid imaging: from healthy aging to Alzheimer's disease," Current Neurology and Neuroscience Reports, vol. 9, no. 5, pp. 345-352, 2009.

[52] C. Soto, E. M. Sigurdsson, L. Morelli, R. A. Kumar, E. M. Castaño, and B. Frangione, " $\beta$-sheet breaker peptides inhibit fibrillogenesis in a rat brain model of amyloidosis: implications for Alzheimer's therapy," Nature Medicine, vol. 4, no. 7, pp. 822-826, 1998.

[53] J. F. Poduslo, G. L. Curran, A. Kumar, B. Frangione, and C. Soto, “ $\beta$-Sheet breaker peptide inhibitor of Alzheimer's amyloidogenesis with increased blood-brain barrier permeability and resistance to proteolytic degradation in plasma," Journal of Neurobiology, vol. 39, no. 3, pp. 371-382, 1999.

[54] L. O. Tjernberg, J. Näslund, F. Lindqvist et al., "Arrest of $\beta$ amyloid fibril formation by a pentapeptide ligand," Journal of Biological Chemistry, vol. 271, no. 15, pp. 8545-8548, 1996.

[55] J. Ghanta, C.-L. Shen, L. L. Kiessling, and R. M. Murphy, "A strategy for designing inhibitors of $\beta$-amyloid toxicity," Journal of Biological Chemistry, vol. 271, no. 47, pp. 29525-29528, 1996.

[56] M. M. Pallitto, J. Ghanta, P. Heinzelman, L. L. Kiessling, and R. M. Murphy, "Recognition sequence design for peptidyl modulators of $\beta$-amyloid aggregation and toxicity," Biochemistry, vol. 38, no. 12, pp. 3570-3578, 1999.

[57] T. Chen, X. Wang, Y. He et al., "Effects of cyclen and cyclam on zinc(II)- and copper(II)-induced amyloid $\beta$-peptide aggregation and neurotoxicity," Inorganic Chemistry, vol. 48, no. 13, pp. 5801-5809, 2009.

[58] J. Suh and W. S. Chei, "Metal complexes as artificial proteases: toward catalytic drugs," Current Opinion in Chemical Biology, vol. 12, no. 2, pp. 207-213, 2008.

[59] K. Ono, K. Hasegawa, H. Naiki, and M. Yamada, "Curcumin has potent anti-amyloidogenic effects for Alzheimer's $\beta$ amyloid fibrils in vitro," Journal of Neuroscience Research, vol. 75, no. 6, pp. 742-750, 2004.

[60] E. K. Ryu, Y. S. Choe, K.-H. Lee, Y. Choi, and B.-T. Kim, "Curcumin and dehydrozingerone derivatives: synthesis, radiolabeling, and evaluation for $\beta$-amyloid plaque imaging," Journal of Medicinal Chemistry, vol. 49, no. 20, pp. 6111-6119, 2006.

[61] J. Kim, H. J. Lee, and K. W. Lee, "Naturally occurring phytochemicals for the prevention of Alzheimer's disease," Journal of Neurochemistry, vol. 112, no. 6, pp. 1415-1430, 2010.

[62] A. A. Reinke and J. E. Gestwicki, "Structure-activity relationships of amyloid beta-aggregation inhibitors based on curcumin: influence of linker length and flexibility," Chemical Biology and Drug Design, vol. 70, no. 3, pp. 206-215, 2007.

[63] M.-P. Kung, C. Hou, Z.-P. Zhuang et al., "IMPY: an improved thioflavin-T derivative for in vivo labeling of $\beta$-amyloid plaques," Brain Research, vol. 956, no. 2, pp. 202-210, 2002.

[64] M.-P. Kung, C. Hou, Z.-P. Zhuang, D. Skovronsky, and H. F. Kung, "Binding of two potential imaging agents targeting amyloid plaques in postmortem brain tissues of patients with Alzheimer's disease," Brain Research, vol. 1025, no. 1-2, pp. 98105, 2004.

[65] M.-P. Kung, C. Hou, Z.-P. Zhuang, A. J. Cross, D. L. Maier, and H. F. Kung, "Characterization of IMPY as a potential imaging agent for $\beta$-amyloid plaques in double transgenic PSAPP mice," European Journal of Nuclear Medicine and Molecular Imaging, vol. 31, no. 8, pp. 1136-1145, 2004.

[66] A. B. Newberg, N. A. Wintering, K. Plössl et al., "Safety, 
biodistribution, and dosimetry of ${ }^{123}$ I-IMPY: a novel amyloid plaque-imaging agent for the diagnosis of Alzheimer's disease," Journal of Nuclear Medicine, vol. 47, no. 5, pp. 748754, 2006.

[67] M.-P. Kung, Z.-P. Zhuang, C. Hou, L.-W. Jin, and H. F. Kung, "Characterization of radioiodinated ligand binding to amyloid $\beta$ plaques," Journal of Molecular Neuroscience, vol. 20, no. 3, pp. 249-253, 2003.

[68] L. Cai, J. Cuevas, S. Temme et al., "Synthesis and structureaffinity relationships of new 4-(6-iodo- $H$-imidazo[1,2a]pyridin-2-yl)- $N$-dimethylbenzeneamine derivatives as ligands for human $\beta$-amyloid plaques," Journal of Medicinal Chemistry, vol. 50, no. 19, pp. 4746-4758, 2007.

[69] H. F. Kung, C.-W. Lee, Z.-P. Zhuang, M.-P. Kung, C. Hou, and K. Plössl, "Novel stilbenes as probes for amyloid plaques," Journal of the American Chemical Society, vol. 123, no. 50, pp. 12740-12741, 2001.

[70] W. Zhang, S. Oya, M.-P. Kung, C. Hou, D. L. Maier, and H. F. Kung, "F-18 stilbenes as PET imaging agents for detecting $\beta$ amyloid plaques in the brain," Journal of Medicinal Chemistry, vol. 48, no. 19, pp. 5980-5988, 2005.

[71] H. F. Kung, S. R. Choi, W. Qu, W. Zhang, and D. Skovronsky, ${ }^{18} \mathrm{~F}$ stilbenes and styrylpyridines for PET imaging of $\mathrm{A} \beta$ plaques in Alzheimer's disease: a miniperspective," Journal of Medicinal Chemistry, vol. 53, no. 3, pp. 933-941, 2010.

[72] J.-S. Choi, J. J. Braymer, R. P. R. Nanga, A. Ramamoorthy, and M. H. Lim, "Design of small molecules that target metal$\mathrm{A} \beta$ species and regulate metal-induced $\mathrm{A} \beta$ aggregation and neurotoxicity," 2010, Proceedings of the National Academy of Sciences of the United States of America. In press. 


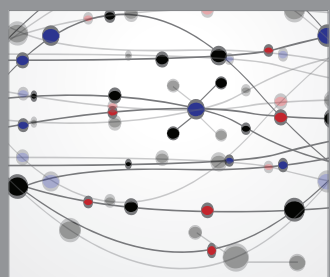

The Scientific World Journal
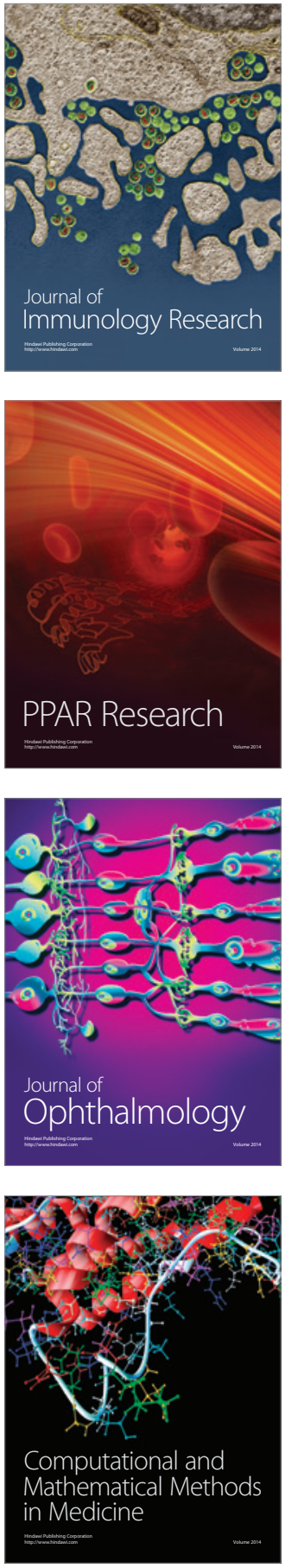

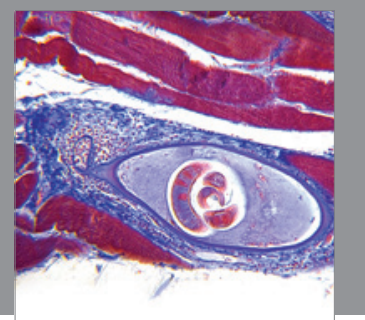

Gastroenterology

Research and Practice


\section{Hindawi}

Submit your manuscripts at

http://www.hindawi.com
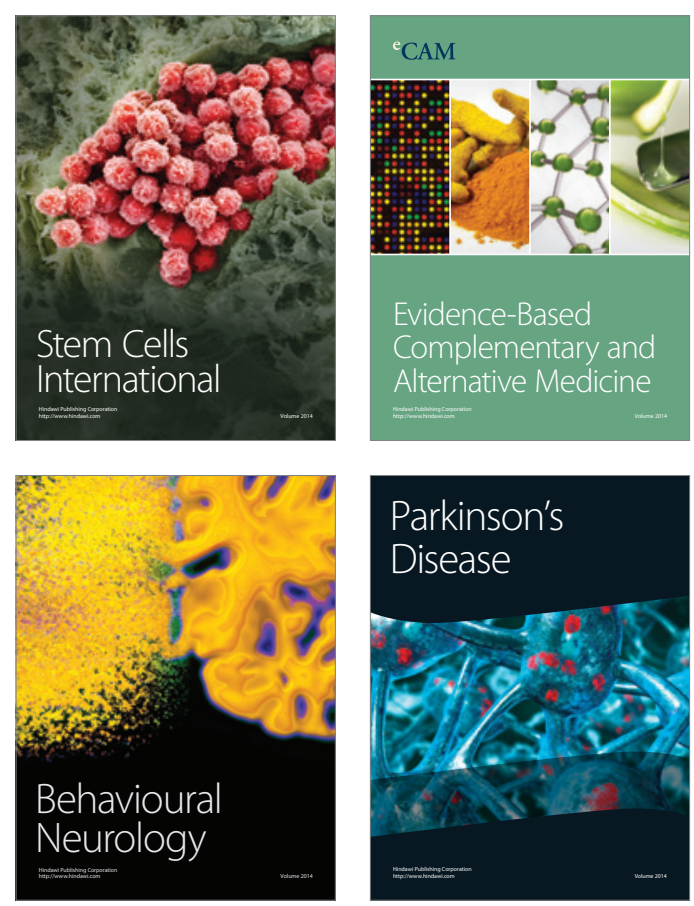



Journal of
Diabetes Research

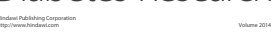

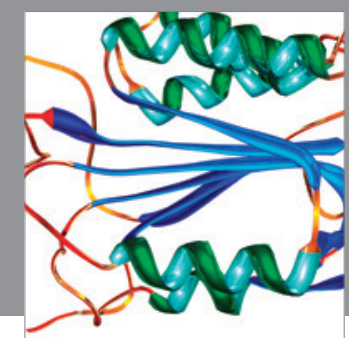

Disease Markers
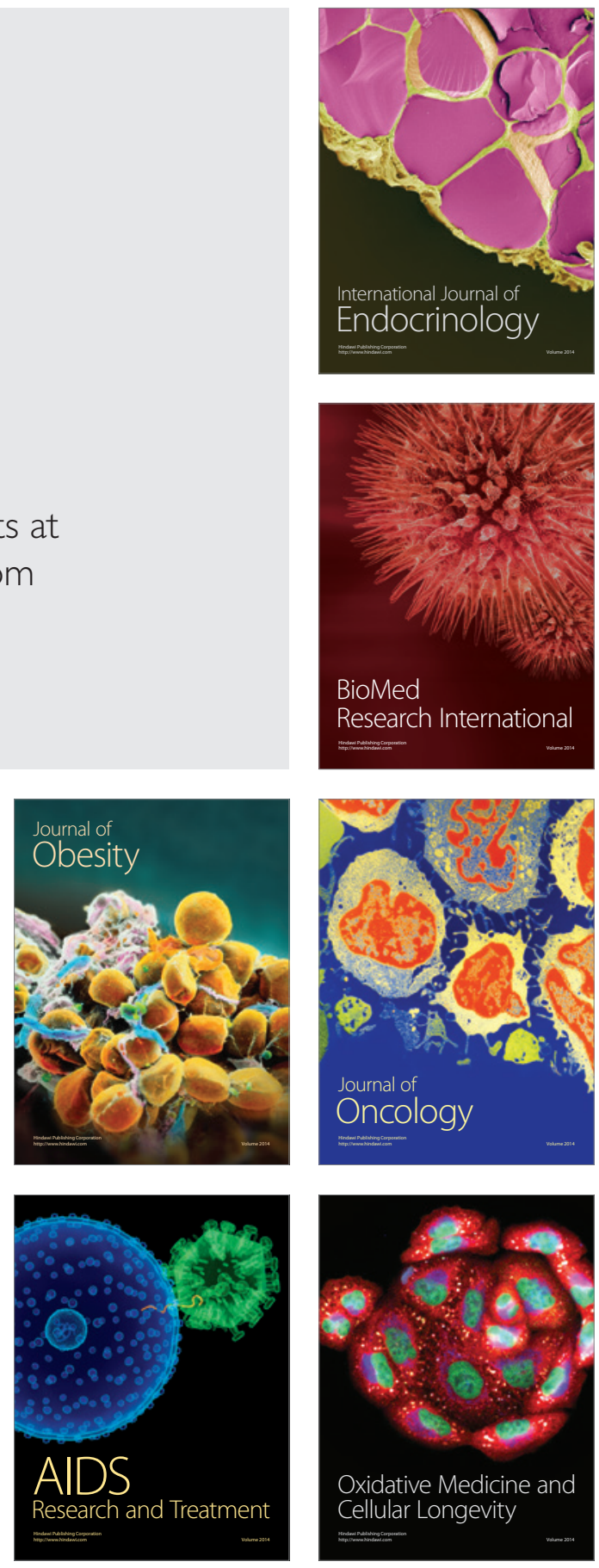